\title{
First human totally endoscopic aortic valve replacement: An early report
}

Marco Vola, MD, PhD, Jean-François Fuzellier, MD, Bertrand Chavent, MD, and Ambroise Duprey, MD, Saint-Etienne, France

From the Department of Cardiovascular Surgery, Centre Hospitalier Universitaire de Saint-Étienne, Saint-Etienne, France.

Disclosures: Marco Vola reports consulting and lecture fees from Medtronic. JeanFrançois Fuzellier reports lecture fees from Medtronic. All other authors have nothing to disclose with regard to commercial support.

Received for publication Aug 12, 2013; revisions received Sept 29, 2013; accepted for publication Oct 6, 2013; available ahead of print Dec 2, 2013.

Address for reprints: Marco Vola, MD, PhD, Cardiovascular Surgery Unit, Centre Hospitalier Universitaire de Saint-Étienne Nord, 42055 Saint-Etienne cedex, France (E-mail: marco.vola@univ-st-etienne.fr).

J Thorac Cardiovasc Surg 2014;147:1091-3

$0022-5223 / \$ 36.00$

Copyright (C) 2014 by The American Association for Thoracic Surgery

http://dx.doi.org/10.1016/j.jtcvs.2013.10.010
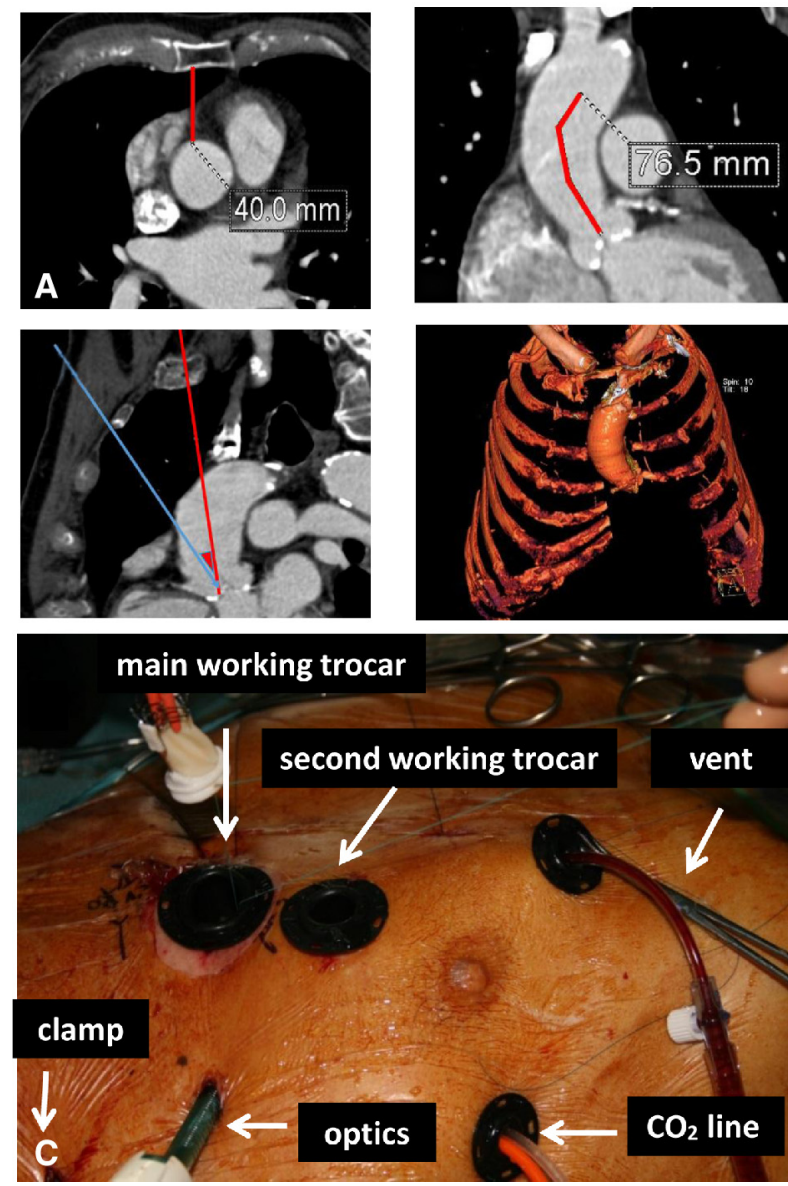

B

Less invasive aortic valve operations through a partial sternotomy or minithoracotomy can be performed with conventional bioprostheses. ${ }^{1,2}$ Totally endoscopic aortic valve replacement (TEAVR) has not previously been feasible, because the currently available designs of stented tissue valves do not allow them to fit through a trocar. The recent advent of sutureless bioprostheses, mounted on a compressible self-expanding nitinol stent, has made this possible. We report the first TEAVR procedures in 2 patients through conventional thoracoscopic trocars.

FIGURE 1. A, Preoperative computed tomographic images of patient 2 demonstrate how to assess and apply the selection criteria. It is recommended to avoid patients with insufficient periaortic working space $(<2 \mathrm{~cm}$ between the inferior margin of the sternum and the aortic anterior wall; top left). To keep a comfortable distance between the aortic clamp, the cardioplegia needle, and the aortotomy, and consequently safe placement of the aortic closing sutures, very short aortas should also be excluded (the central line of the ascending aorta should be longer than $5 \mathrm{~cm}$; top right). Vertical aortas without physiologic curvature should be avoided; the central axis of the proximal aortic root (bottom left, red line), together with the operative axis of the third intercostal space (bottom left, blue line), should create an angle not exceeding $45^{\circ}$, to avoid any traction onto the margins of the aortotomy when instruments are inserted in the aortic root through the trocars. The last panel (bottom right) shows a 3-dimensional reconstruction of the computed tomographic scan. B, Patient 1's aortotomy can be seen on the screen. C, Intraoperative photograph of patient 2 shows operating field and trocar positioning. The main working trocar ( $20 \mathrm{~mm})$ is in the second intercostal space, a second operative trocar $(15 \mathrm{~mm})$ is in the third, a percutaneous transthoracic aortic clamp is in the first, a 5 - $\mathrm{mm} 30^{\circ}$ optic is in the second (7 mm trocar), and a right pulmonary vein venting line and purse-string with carbon dioxide insufflation line are in the fifth (both with a 7 mm trocar). D, Patient 2 is shown on postoperative day 4. 

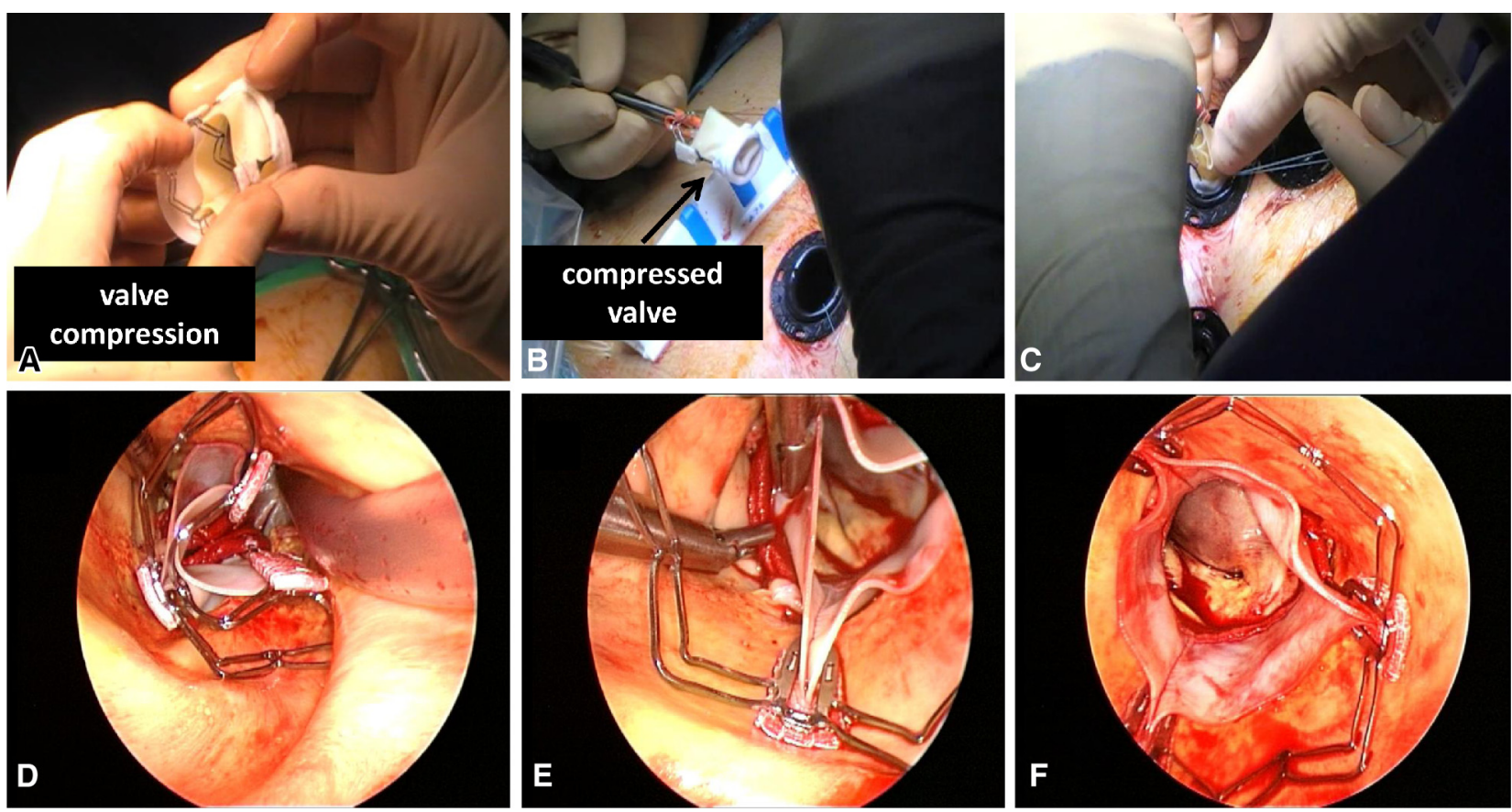

FIGURE 2. Procedural steps of the sutureless bioprosthesis. A, Sutureless bioprosthesis ready for compression. B, Compressed valve ready to be inserted in the trocar. C, Sutureless bioprosthesis passage through the main operative 20-mm trocar. D, Sutureless bioprosthesis compressed and inserted into the aortic root after removal of the native aortic valve. E, Sutureless bioprosthesis, endoscopic decompression, and adjustment into the aortic annulus. F, Complete expansion of the sutureless valve into the aortic root.

\section{CLINICAL SUMMARY}

Proof-of-concept of TEAVR was first achieved in cadavers, and institutional ethics committee approval and patients' consent were obtained before the operation. The first patients treated, patients 1 and 2, were male, aged 83 and 82 years, respectively, and had aortic valve stenosis. Preoperative mean transvalvular aortic valve gradient, ejection fraction, and body surface area were 52 and $47 \mathrm{~mm} \mathrm{Hg}$, $61 \%$ and $45 \%$, and 1.97 and $2.00 \mathrm{~m}^{2}$, respectively. Preoperative thoracic computed tomography was used to assess the degree of calcification and anatomic suitability (Figure 1, A). Suitable patients have a long $(\geq 5 \mathrm{~cm})$ ascending nonvertical aorta (with a physiologic curvature), with sufficient periaortic working space $(\geq 2 \mathrm{~cm})$ between the sternum and the aortic wall. We also used the computed tomographic scan to measure the diameter of the aortic annulus, which was compared with the transesophageal echocardiographic findings of 2 independent operators to determine the appropriate size of the bioprosthesis. For both procedures, under selective ventilation, 5 trocars (Flexipath; Ethicon, Inc, Somerville, NJ) were introduced in the right hemithorax (Figure 1) and femorofemoral cardiopulmonary bypass (CPB) was initiated. After transcutaneous aortic crossclamping (Chitwood clamp; Geister, Tuttlingen, Germany), antegrade cardioplegia (histidine-tryptophanketoglutarate cardioplegic solution; Kohler Chemie, Alsbach-Hahnlein, Germany) and aortotomy, valvular and annular calcifications were removed. Both patients received 3f Enable sutureless aortic bioprostheses (Medtronic, Inc, Minneapolis, Minn), $27 \mathrm{~mm}$ and $23 \mathrm{~mm}$, respectively, each reduced to $19 \mathrm{~mm}$ by compression of the nitinol stent and introduced into the main trocar $(20 \mathrm{~mm})$. In each patient, the appropriate valve was inserted into the ascending aorta and expanded and fixed in the annulus (Figure 2). Air embolism was prevented through continuous insufflation of carbon dioxide. After closure of the aorta, reinsertion of an aortic vent, and left table tilting, we monitored deairing of residual bubbles in the ventricle under transesophageal echocardiographic control. Aortic crossclamping and CPB times were 102 and 145 minutes in the first patient and 110 and 150 minutes in the second patient, respectively. An intraoperative transesophageal echocardiogram confirmed the absence of paravalvular leakages. Hospital discharge was uneventful in both cases (both after 7 days), and no surgical revision, stroke, myocardial infarction, renal insufficiency, pacemaker implantation, or other complications were reported.

\section{DISCUSSION}

In our institution, moving toward a less invasive technique has required a stepwise approach, starting with the adoption of the ministernotomy technique as routine. We then transitioned to the right minithoracotomy approach, first under direct view, then with an endoscopic camera, 
and, finally, by means of a totally endoscopic technique. It is important to note that when performing a totally endoscopic procedure, a quick and safe conversion to minithoracotomy under direct view can be made if circumstances demand, which would still offer significantly reduced chest trauma.

Totally endoscopic surgery in other fields, such as atrial septal defect repair and coronary artery bypass grafting, has shown improved quality of life but with longer clamping and CPB times during the learning curve., Considering that the TEAVR cases described here were our first procedures, we believe that clamping and CPB times were acceptable and suggest that the learning curve associated with TEAVR could be shorter than that reported with totally endoscopic coronary artery bypass grafting. The potential of this approach could be further enhanced by the development of endoscopic sizers as well as dedicated instruments for decalcification.

Second-generation sutureless bioprostheses could also simplify implantation, although this did not require more than 45 minutes in either patient. Devices to facilitate a technically demanding aortotomy closure are also critically important. In fact, closing the aorta consumed more than $30 \%$ of the clamping time in both cases, despite the fact that we selected patients with adequate working space around the ascending aorta. Last but not least, surgical robots may offer additional benefits to the totally endoscopic approach. Previously, only a proof-of-concept in cadavers ${ }^{5}$ through a standard minithoracotomy access has been published.

\section{CONCLUSIONS}

These first procedures show that totally endoscopic sutureless aortic valve replacement is technically feasible. Further clinical experience and technical development are necessary to shorten operation times and to assess further the potential postoperative benefits of TEAVR.

We thank Dr Antoine Gerbay and Dr Marie Levallois for the echocardiographic support.

\section{References}

1. EIBardissi AW, Shekar P, Couper GS, Cohn LH. Minimally invasive aortic valve replacement in octogenarian, high-risk, transcatheter aortic valve implantation candidates. J Thorac Cardiovasc Surg. 2011;141:328-35.

2. Glauber M, Miceli A, Gilmanov D, Ferrarini M, Bevilacqua S, Farneti PA, et al. Right anterior minithoracotomy versus conventional aortic valve replacement: a propensity score matched study. J Thorac Cardiovasc Surg. 2013;145:1222-6.

3. Morgan JA, Peacock JC, Kohmoto T, Garrido MJ, Schanzer BM, Kherani AR, et al. Robotic techniques improve quality of life in patients undergoing atrial septal defect repair. Ann Thorac Surg. 2004;77:1328-33.

4. Bonaros N, Schachner T, Lehr E, Kofler M, Wiedemann D, Hong P, et al. Five hundred cases of robotic totally endoscopic coronary artery bypass grafting: predictors of success and safety. Ann Thorac Surg. 2013;95:803-12.

5. Suri RM, Burkhart HM, Schaff HV. Robot-assisted aortic valve replacement using a novel sutureless bovine pericardial prosthesis: proof of concept as an alternative to percutaneous implantation. Innovations (Phila). 2010;5:419-23.

\title{
Sternal elevation before passing bars: A technique for improving visualization and facilitating minimally invasive pectus excavatum repair in adult patients
}

\author{
Dawn E. Jaroszewski, MD, ${ }^{\mathrm{a}, \mathrm{b}}$ Kevin Johnson, MD, ${ }^{\mathrm{a}}$ Lisa McMahon, MD, ${ }^{\mathrm{a}, \mathrm{b}}$ and David Notrica, MD, ${ }^{\mathrm{a}, \mathrm{b}}$ \\ Phoenix, Ariz
}

Minimally invasive repair of pectus excavatum (MIRPE) is performed by placement of substernal metal bars. Visualization across the mediastinum is compromised in severe defects, and cardiac puncture and aortic injury have been described. ${ }^{1}$ In adults with less chest wall flexibility, the

From the Division of Cardiothoracic Surgery, ${ }^{a}$ Department of Surgery, Mayo Clinic Arizona, Phoenix, Ariz; and Department of Surgery, ${ }^{\mathrm{b}}$ Phoenix Children's Hospital, Phoenix, Ariz

Disclosures: Authors have nothing to disclose with regard to commercial support. Received for publication April 18, 2013; revisions received July 10, 2013; accepted for publication Sept 25, 2013; available ahead of print Nov 18, 2013.

Address for reprints: Dawn E. Jaroszewski, MD, Mayo Clinic, 5777 E Mayo Blvd,

Phoenix, AZ 85054 (E-mail: jaroszewski.dawn@mayo.edu).

J Thorac Cardiovasc Surg 2014;147:1093-5

$0022-5223 / \$ 36.00$

Copyright (c) 2014 by The American Association for Thoracic Surgery

http://dx.doi.org/10.1016/j.jtcvs.2013.09.049 bars require more force to rotate and intercostal muscle stripping may result, leading to bar malpositioning. We present a technique to elevate the sternum and facilitate adult MIRPE.

\section{PROCEDURE}

The patient is positioned supine, rolls underneath, and arms tucked at sides. Bilateral incisions and subpectoral pockets are developed. Ports are placed through the incision and inferior-lateral above the diaphragm. Cardiac compression is assessed thoracoscopically. If safe dissection is potentially compromised by defect (Figure 1,A), a bone clamp is placed into the sternum and a table-mounted retractor is used to elevate the sternum (Figure 1, B). Patients with significant cartilage calcification and rigidity 